\title{
Interactive comment on "Observations and explicit modeling of isoprene chemical processing in polluted air masses in rural areas of the Yangtze River Delta region: radical cycling and formation of ozone and formaldehyde" by Kun Zhang et al.
}

Anonymous Referee \#2

Received and published: 23 October 2020

Summary: Air quality has become a serious issue in China. This study collected ambient concentration of several pollutants (e.g., $\mathrm{O} 3$ and $\mathrm{HCHO}$ ) as well as precursors (NOx and VOCs) in a rural site of YRD in summer 2018 and applied an observationbased model (OBM) with MCM to investigate the impact of isoprene emissions on two oxidants: ozone and formaldehyde for five selected days. The way of evaluating the potential role of isoprene is based on changes of several simulated ROx radicals by removing isoprene from the 5-day baseline modeling from the baseline. It concludes that isoprene plays an important role in formation of ozone and formaldehyde since the 
reduction of $\mathrm{ROx}$ radicals is significant when isoprene is removed.

The manuscript is reasonable written and consists of details needed to support the analysis and conclusions. However, several key questions need to be addressed before publication, as follows.

1) The title of manuscript "Observations and explicit modeling of isoprene chemical processing in polluted air masses in rural areas of the Yangtze River Delta region: radical cycling and formation of ozone and formaldehyde" is not well supported by the work presented. The observations are limited since key product species (i.e., MACR and $\mathrm{MVK}$ ) and ROx radicals of isoprene were not measured or observed.

2) Is DSH a rural site? It is characterized as suburban by Lin et al. (2020) and impacted by a nearby freeway. Lin et al. (2020) indicate that both DSH and PD (urban site) are dominated by vehicle emissions sites (Figure 10) and isoprene emission is less in DSH than PD (Figure 5)? Can analysis be done for these five episodes in this study to demonstrate isoprene dominates among VOCs? Otherwise, it is hard to justify the study objective.

3) Model performance (i.e., OBM in this study) should be conducted against observed key species such as ozone, formaldehyde, and NOx before the model can be confidently used to simulate other key $\mathrm{RO}$ species such as $\mathrm{OH}, \mathrm{HO} 2, \mathrm{RO}$, and $\mathrm{RO} 2$ (e.g., Figures 4, 5, 7-8). For instance, simulated local $\mathrm{O} 3$ is shown in Figure 7(A) but correlative discussion with observed $\mathrm{O} 3$ profile is needed. Similarly, simulated $\mathrm{HCHO}$ concentration in Figure 8(A) should be correlated with observed $\mathrm{HCHO}$ concentration. Without solid performance evaluation, simulated $\mathrm{ROx}$ radicals are questionable although they are comparable to other literature values, as indicated in this study.

4) As mention above, ROx radicals and key products (i.e., MACR and MVK) photochemically produced by isoprene and other precursors were not measured so model performance couldn't be conducted against these species. Without the validation, this is hard to evaluate the simulated ROx radicals with confidence, as mentioned above. 
In addition, over 50 VOCs were measured but they were not utilized in this study. As an example, some VOCs primarily react with $\mathrm{OH}$ radical so those VOCs can be used as surrogates to estimate concentration of $\mathrm{OH}$ radicals, which can then be compared to simulated $\mathrm{OH}$ radicals. For example, Lin et al (2020) used X/E to estimate $\mathrm{OH}$. Another analysis of VOC data can be conducted to evaluate the relative importance of isoprene in total VOCs. Isoprene has to be a significant part of VOCs emissions in order to achieve the objective of this study, evaluating isoprene's importance in rural areas.

5) Measurements of VOCs are described in details (Lines 116-125) but VOC analysis is lacking. Additional analysis would be useful. For instance, several types of VOCs (e.g., alkenes and aromatics) contribute to OVOC, an important specie focused in this study (in Figures 6 and 9), so their relationship to OVOC can be evaluated, in addition to the VOC analyses suggested above.

Technical comments:

1) Table 1: SO2 is listed as one of the measured pollutants but it is not used in this study at all. Please remove it from the table. $\mathrm{CO}$ is not listed here but shown in Figure 2.

2) Figure 2: $\mathrm{CO}$ concentration is almost flat so indicates this site is less impacted by traffic-related emissions. This contradicts with Lin et al (2020)'s observation (Figure 3), where NOx concentrations show traffic related variation in $\mathrm{DSH}$.

3) Section 3.3 (line 210+): there is no discussion or description of Figure 5(B).

4) Figure 8: Net $\mathrm{HCHO}$ rate is negative for several hours around noon. What does that mean? Some discussion is needed.

5) Figures 6 and 9: It seems the red lines indicate photolysis production of ROx radicals while blue lines destruction or sink of these radicals. What does the black line represent? Some description is needed.

Minor comments: 
1) Line 184: should be "series", not "serious"

2) Lines 512 and 517: these two references seemk identical.

3) Term "loss" is used in Figure 5 and its associated text while "destruction" or "sink" in Figures 7 and 8 and their description. They probably meant the same thing but consistency is preferred.

Interactive

comment

4) Line 205: "by separate the formation of RO2" should be revised for clarity. Do you mean "by separation from the formation of RO2"?

5) Line 263-264, the last sentence should be "Primary ROx sources and sinks are in red and blue, respectively."

Interactive comment on Atmos. Chem. Phys. Discuss., https://doi.org/10.5194/acp-2020-728, 2020. 